\title{
Improved methodology for non-covalent immobilization of tert-butyl- azabis(oxazoline)-copper complex on Al-MCM41
}

\author{
Robert A. Feldman, José M. Fraile*
}

Instituto de Síntesis Química y Catálisis Homogénea (ISQCH), Facultad de Ciencias, C.S.I.C. - Universidad de Zaragoza, E-50009 Zaragoza, Spain. E-mail:

jmfraile@unizar.es

\begin{abstract}
Copper sites are supported on Al-MCM41 by thermally treating copper(II) triflate that was deposited using the incipient wetness method. The change of the chemical state of the triflate anions following thermal treatment is monitored using TGA and SEM-EDX. Thermal treatment yields copper sites that then can be modified with chiral tert-butylazabis(oxazoline) by adding a solution of this ligand to the support using incipient wetness. The catalyst produced in this way is efficient and stable with good enantioselectivity, and can be used in the cyclopropanation of styrene with ethyl diazoacetate under conditions employing an elevated temperature. The use of thermal treatment in the catalyst preparation method produces catalysts that are superior to the solids prepared by cation exchange or incipient wetness of the pre-formed complex.
\end{abstract}

Keywords: asymmetric catalysis; immobilized catalysts; mesoporous materials; bis(oxazolines); copper; 


\section{Introduction}

Ordered mesoporous materials have been described as supports for single-site catalysts [1] due to their well-defined textural properties that include their pore size, high surface area and pore geometry. Chiral catalysts have been immobilized on ordered mesoporous materials either by covalent bonding or by utilizing non-covalent interactions between the chiral complex and the support [2-4]. Through these strategies, effects on selectivity have been observed and explained by the restrictions that their pores impose on the trajectories of approach of the reacting species to the catalytic center $[5,6]$.

In homogeneous catalysis, bis(oxazolines) and other related compounds are among the most useful chiral ligands for enantioselective reactions [7] and in efforts to capitalize on the applications of these ligands as supported catalysis, they have been immobilized on different supports, using a multitude of methods [8-10]. Examples described in the literature utilizing ordered mesoporous materials are relatively uncommon but they exist for the covalent immobilization of complexes on different materials, such as mesocellular foam silicas [11-15], MCM41 and MCM48 [16], hierarchically-ordered mesocellular mesoporous silica [17], SBA15 and HMS [18,19], and a periodic mesoporous phenylene-silica [20]. To date, a few examples are described using noncovalent methods of immobilization, such as the hydrogen bonding of ion-tagged bis(oxazoline) ligands on SBA15 [21] and electrostatic interactions with Al-MCM41 and Al-SBA15 [22] or Al-TUD1 [23]. This limited number of examples contrasts with those dealing with the non-covalent immobilization of other types of complexes, such as Mn(salen) [24,25] or Rh-phosphines [26,27], on mesoporous ordered materials [4]. In our previous work [28] we demonstrated how the cation-exchange process, which successfully immobilized bis(oxazoline)- and azabis(oxazoline)-copper complexes on clays (layered materials) through electrostatic interactions [29-31], was not suitable when applied using the anionic mesoporous materials Al-MCM41 and Al-HMS. The best results were obtained when the complex was introduced into the mesoporous network by incipient wetness, probably due to diffusion problems in the cation exchange process. A conceptual downside of this approach is that it does not allow the separation of the triflate anions from the catalytic centres, and so the true nature of the complex-support interaction is likely to be quite complicated. Indeed, the observations 
pointed to there being more than one type of catalytic site, and moreover, the immobilized catalysts could not be used for more than a few cycles.

Looking to improve the approach, we hypothesized that incipient wetness of the support with a solution of a copper salt would ensure that at least most of the copper would be deposited inside the porous network, and in the most uniform manner possible. The subsequent thermal treatment would then convert the copper counter anion to a stable form that would bind the copper sites firmly to the support. A similar idea had in fact already been described by Hutchings and coworkers [22,32-34] for $\mathrm{Cu}$-exchanged zeolites and mesoporous materials, using the thermal treatment of copper(II) acetate at $550^{\circ} \mathrm{C}$, followed by treatment with bis(oxazoline) ligands. Nonetheless, in our hands it was not possible to prepare stable catalysts following the same process with our AlMCM41 supports. We decided to continue using copper(II) triflate, which is soluble in polar organic solvents and additionally, we preferred impregnation by incipient wetness because it is very quick to implement and gives one precise control over the final cation loading.

Herein, we describe the preparation of a supported copper catalyst prepared with the deposition of a copper precursor on Al-MCM41 by incipient wetness and thermal treatment. The copper sites were then subsequently modified by $(S)$-tert-butylazabis(oxazoline) ligand ( $\mathrm{aza}^{\mathrm{t}} \mathrm{Bu}$ ), and the catalyst used in the enantioselective cyclopropanation reaction of styrene with ethyl diazoacetate (EDA).

\section{Experimental}

\subsection{Preparation of the catalysts}

Al-MCM41 $(\mathrm{Si} / \mathrm{Al}=15)$ was prepared from sodium aluminate and fumed silica in a basic medium with cetyl trimethyl ammonium as the template [35]. To expand the pore size in the synthesis of Al-MCM41 $(\mathrm{Si} / \mathrm{Al}=10), 1,3,5$-trimethylbenzene was added to the gel [36].

\subsubsection{Preparation of $\mathrm{Cu}-\mathrm{Al}-\mathrm{MCM} 4 \mathrm{1}$.}


Al-MCM41 (500 mg) was added to a solution of copper(II) triflate (42 mg, $0.1 \mathrm{mmol})$ in methanol (600 $\mu \mathrm{L}$ for Al-MCM41(10), and $300 \mu \mathrm{L}$ for Al-MCM41(15)) and the container was shaken to ensure that the solution was evenly distributed. This material was then calcined $\left(1^{\circ} \mathrm{C} / \mathrm{min}\right.$ heating until $450^{\circ} \mathrm{C}$, maintained for $\left.4 \mathrm{~h}\right)$ under a 100 $\mathrm{mL} / \mathrm{min}$ flow of either argon or air to obtain $\mathrm{Cu}-\mathrm{Al}-\mathrm{MCM} 41(\mathrm{X})(\mathrm{Ar})$ or $\mathrm{Cu}-\mathrm{Al}-$ MCM41(X)(air) respectively (where $\mathrm{X}$ is the $\mathrm{Si} / \mathrm{Al}$ ratio of Al-MCM41).

\subsubsection{Modification with chiral ligand.}

$\mathrm{Cu}-\mathrm{Al}-\mathrm{MCM} 41(500 \mathrm{mg}, 0.1 \mathrm{mmol} \mathrm{Cu})$ was added to a solution of azat $\mathrm{Bu}(0.2 \mathrm{mmol})$ in dichloromethane $(600 \mu \mathrm{L}$ for Al-MCM41(10), and $300 \mu \mathrm{L}$ for Al-MCM41(15)), the container was shaken to ensure that the ligand was evenly distributed, and this solid was then immediately used as a catalyst.

\subsection{Characterization methods}

The adsorption-desorption isotherms of nitrogen at $77 \mathrm{~K}$ were measured using either a Micromeritics ASAP 2000 or an ASAP 2020 instrument. Each sample was outgassed at $250^{\circ} \mathrm{C}$ after being calcined until a stable static vacuum of $3 \times 10^{-3}$ torr was reached. Particle morphology was observed using a Hitachi S-4500 I scanning electron microscope (SEM) and the composition was determined using energy-dispersive X-ray spectroscopy (EDX). Thermogravimetric analysis (TGA) was carried out in a SDT2960 thermobalance (TA Instruments), heating from room temperature to $500^{\circ} \mathrm{C}$ at $10^{\circ} \mathrm{C} / \mathrm{min}$ in oxygen. Onset temperature $\left(\mathrm{T}_{1}\right)$, maximum derivative temperature $\left(\mathrm{T}_{\mathrm{m}}\right)$ and the temperature of plateau start $\left(\mathrm{T}_{2}\right)$ were used to characterize TGA profiles.

\subsection{Catalytic tests}

\subsubsection{Homogeneous cyclopropanation.}

At room temperature, EDA $(2.5 \mathrm{mmol}, 285 \mathrm{mg})$ dissolved in dichloromethane $(0.5 \mathrm{~mL})$ was added over the course of $2 \mathrm{~h}$ with a syringe pump to a solution containing the copper catalyst $(0.025 \mathrm{mmol})$, $\mathrm{n}$-decane $(100 \mathrm{mg})$ and styrene $(2 \mathrm{~mL}$ for reactions in 
excess of alkene or $2.5 \mathrm{mmol}, 260 \mathrm{mg}$, in $2 \mathrm{~mL}$ dichloromethane for stoichiometric reactions). After the addition, the reaction was left to stir for $30 \mathrm{~min}$ and then analysed by CG [28-31].

\subsubsection{Heterogeneous cyclopropanation.}

The supported catalyst $(100 \mathrm{mg}$, around $0.02 \mathrm{mmol} \mathrm{Cu})$ was suspended in either styrene or dichloromethane $(2 \mathrm{~mL})$ with $\mathrm{n}$-decane $(100 \mathrm{mg})$ and the mixture was heated at the required temperature. $\mathrm{EDA}(2.5 \mathrm{mmol}, 285 \mathrm{mg})$ dissolved in dichloromethane $(0.5 \mathrm{~mL})$ was added over the course of 15 min with a syringe pump. After the addition, the catalyst was separated by centrifugation, the products were analyzed by GC, and the next reaction was performed by immediately re-suspending the catalyst in the same solvent.

\subsubsection{Continuous flow reaction.}

A stainless steel HPLC column $(150 \mathrm{~mm} \times 46 \mathrm{~mm}$ i.d.) was completely filled using 500 $\mathrm{mg}$ of $\mathrm{Cu}-\mathrm{Al}-\mathrm{MCM} 41(10)($ air $)$ and it was sealed with frits (porosity of $2.0 \mu \mathrm{m}$ ). The column was placed in an oven at $120^{\circ} \mathrm{C}$ for $12 \mathrm{~h}$ prior to being used. For the modification with the chiral ligand, a solution of azatBu $(20 \mathrm{~mL}, 0.01 \mathrm{M})$ in the chosen solvent was charged into a $25 \mathrm{~mL}$ gas tight syringe, fitted with a $51 \mathrm{~mm}$ metal hub needle, and connected to the HPLC column via a Luer Lock Valve Adaptor. This solution was then fed through the column using a syringe pump. As an example of operation, a feed of styrene $(4.5 \mathrm{~g}, 43 \mathrm{mmol})$, decane $(0.1 \mathrm{~g}, 0.5 \mathrm{mmol})$ and EDA $(0.3 \mathrm{~g}$,

$2.5 \mathrm{mmol}$ ) was passed through a column of unmodified $\mathrm{Cu}-\mathrm{Al}-\mathrm{MCM} 41(10)($ air $)$ at a flow rate of $1 \mathrm{~mL} / \mathrm{h}$. Different fractions were collected along the operation time and they were then analysed individually by GC.

\section{Results and discussion}

\subsection{Preparation and characterization of Cu-Al-MCM41}


The Al-MCM41 supports were prepared by established methods $[35,36]$ and came from the same batches of the supports used in our previous paper [28]. Copper(II) triflate dissolved in methanol was introduced into each Al-MCM41 sample $(\mathrm{Si} / \mathrm{Al}=10$ or 15$)$ using incipient wetness impregnation [28] and then thermally treated. The hypothesis was that thermal treatment would convert copper(II) triflate into a stable form that would be strongly bound to the surface of the support.

With the goal of trying to characterize the changes that took place during thermal treatment, a thermogravimetric study was performed with $\mathrm{Cu}(\mathrm{OTf})_{2}$ in its pure form, and deposited on different supports, to identify where the transition points $\left(T_{1}, T_{m}, T_{2}\right)$ would occur. The principle is that if there should be even a partial electrostatic interaction between the copper and the support, this would generate a chemical state whose TGA would be distinguishible from the pure material by its different temperature transition points. Furthermore, one would anticipate that the extent of the change would vary in parallel with the strength of the interaction.

The TGAs of copper(II) triflate in pure form and deposited on pure silica materials (Figure 1) produce the $T_{1}, T_{m}, T_{2}$ values that are summarized in Table 1. A property seen with pure copper(II) triflate is that there are two separate weight losses at $100^{\circ} \mathrm{C}$ and $120^{\circ} \mathrm{C}$ that probably correspond to a two step loss of water, also seen in the dehydration of copper methanesulfonate [37]. These signals are well below the temperature at which the triflate decomposes $\left(460^{\circ} \mathrm{C}\right)$ and therefore, they should not interfere with this region. When lanthanide (III) triflates undergo thermal decomposition the corresponding lanthanide fluoride is produced (Eq. 1) [38], and the same is supposed to happen with copper(II) triflate. The weight-loss in the decomposition of copper(II) triflate is $65 \%$, which is close to the theoretical weight loss of $72 \%$ that would be expected from the conversion to copper(II) fluoride.

(Eq. 1) $\mathrm{Ln}\left(\mathrm{CF}_{3} \mathrm{SO}_{3}\right)_{3} \rightarrow \mathrm{LnF}_{3}+3 \mathrm{SO}_{2}+\mathrm{CO}_{2}+\mathrm{CF}_{3} \mathrm{OCF}_{3}$

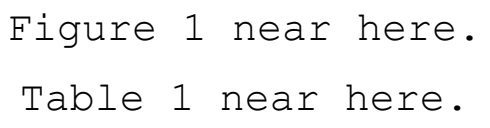

Copper(II) triflate was deposited on two samples of chromatography-silica $\left(500 \mathrm{~m}^{2} / \mathrm{g}\right)$ with different particle size, and MCM41, using a copper loading of $1.5 \mathrm{wt} \% \mathrm{Cu}$. These 
materials do not contain aluminium and therefore, one would anticipate a weak mode of interaction between silica and the triflate, such as hydrogen bonding. Indeed, the TGA shows that there is a detectable interaction, since the $\mathrm{T}_{\mathrm{m}}$ of the supported $\mathrm{Cu}(\mathrm{OTf})_{2}$ in all the three cases is lower than that of the pure salt (Table 1). It can be seen that $T_{m}$ for the chromatography silicas is at around $360^{\circ} \mathrm{C}$, which is $100^{\circ} \mathrm{C}$ lower than pure copper(II) triflate. This finding might not be unexpected considering it was similarly found that there is a decrease in the temperature transition points when copper(II) triflate was supported on Kieselgel-K100 [39]. In that case, the explanation for the drop in $\mathrm{T}_{\mathrm{m}}$ is that triflic acid was formed following the cation-exchange and this decomposes at around $380^{\circ} \mathrm{C}[40]$. The curve produced when MCM41 is the support stands out from the chromatography-silicas, since its $\mathrm{T}_{\mathrm{m}}$ value is at around $400^{\circ} \mathrm{C}$ and is so broad that it eclipses both the decomposition regions of the chromatography silicas and the decomposition of pure $\mathrm{Cu}(\mathrm{OTf})_{2}$. Based on this it could be inferred that there are at least two types of interaction going on, which are the interaction of isolated copper(II) triflate with the silica wall, and secondly, there are probably clusters of non dispersed copper(II) triflate. Thus, under these circumstances the chromatography silicas provided a more efficient level of dispersion, which is surprising given the difference in surface areas (1000 vs $\left.500 \mathrm{~m}^{2} / \mathrm{g}\right)$. The culprit could be a confinement effect inside the pores of MCM-41 that prevents the copper from dispersing.

When the same amount of $\mathrm{Cu}$ is deposited on Al-MCM41(15) the decrease in the $\mathrm{T}_{\mathrm{m}}$ value $\left(306^{\circ} \mathrm{C}\right)$ is even more significant (Table 1) and would seem to indicate the existence of copper/aluminium interaction that is likely to be electrostatic in nature. Due the use of sodium aluminate in the precursor gel for Al-MCM41, the aluminium sites are counter-balanced by sodium cations. This means that triflic acid would not be expected to be liberated from the copper(II) triflate and this is confirmed by the much higher decomposition point of triflic acid $\left(380^{\circ} \mathrm{C}\right)$ [40]. Pure sodium triflate decomposes between $253^{\circ} \mathrm{C}$ and $256^{\circ} \mathrm{C}$ [41] and therefore, the formed species must not be sodium triflate either. Therefore, it seems reasonable that what actually happens when copper(II) triflate is added to our support is that the place of sodium cation is taken up by an ion par such as $\left[\mathrm{CuNa}(\mathrm{OTf})_{2}\right]^{+}$.

To examine this idea, the behaviour of another metal triflate was tested. Thus, zinc (II) triflate was deposited (1.5 wt $\% \mathrm{Zn})$ on Al-MCM41(15) and assessed by TGA. The finding was that it gave the same $\mathrm{T}_{\mathrm{m}}$ value as supported $\mathrm{Cu}(\mathrm{OTf})_{2}$ (around $310^{\circ} \mathrm{C}$ ), 
whereas the $\mathrm{T}_{\mathrm{m}}$ value of pure $\mathrm{Zn}(\mathrm{OTf})_{2}$ is significantly higher than $\mathrm{Cu}(\mathrm{OTf})_{2}, 528^{\circ} \mathrm{C} v s$ $460^{\circ} \mathrm{C}$ respectively (Table 1 ). The $\mathrm{T}_{\mathrm{m}}$ value obtained when the two salts are deposited on Al-MCM41 would indicate that both triflates interact with the support in the same way.

The composition ( $\mathrm{Si} / \mathrm{Al}$ ratio) and textural properties (surface area and porosity) of AlMCM41 do not modify the behaviour of supported $\mathrm{Cu}(\mathrm{OTf})_{2}$ assessed by TGA (Table 1). On the other hand, the level of copper loading does have some influence. Different copper loadings were added to Al-MCM41(15) to see if TGA could reveal anything about the maximum loading capacity of the support. At loadings equal to $3 \mathrm{wt} \%$ or below, the decomposition temperatures are the same $\left( \pm 2^{\circ} \mathrm{C}\right)$, whereas at loadings higher than $3 \mathrm{wt} \%$ the $\mathrm{T}_{\mathrm{m}}$ and $\mathrm{T}_{2}$ temperatures increase. It can be deduced that $0.5 \mathrm{mmol} \mathrm{Cu}$ per gram of support saturates the Al sites in Al-MCM41(15), which contains around 1 mmol Al per gram. Beyond this level, from the increase witnessed in the value of $T_{m}$, it appears that $\mathrm{Cu}(\mathrm{OTf})_{2}$ begins to interact more with the silica walls of the support. For the actual preparation of the catalyst (denoted as $\mathrm{Cu}-\mathrm{Al}-\mathrm{MCM} 41$ ), $450^{\circ} \mathrm{C}$ was chosen as the temperature used for the thermal treatment since it is high enough to finish the decomposition of the triflate anion.

A semiquantitative analysis was carried out by SEM-EDX, with the goal of seeing whether the preparation method would achieve a homogeneous distribution of copper and to further characterise the species on the support. Given the known empirical composition of the synthesis gel, the analysis of $\mathrm{Cu}-\mathrm{Al}-\mathrm{MCM} 41(10)$ and $\mathrm{Cu}-\mathrm{Al}-$ MCM41(10) gave $\mathrm{Si} / \mathrm{Al}$ ratios lower than expected, and the $\mathrm{O} /(\mathrm{Si}+\mathrm{Al})$ ratios were higher. These two disparities are explained by an understimation of the silicon content analyzed by EDX. On the other hand, the $\mathrm{Cu} / \mathrm{Al}$ ratios were close to the value that corresponds to $1.5 \mathrm{wt} \% \mathrm{Cu}$ added in the impregnation process $(1.7 \mathrm{wt} \% \mathrm{Cu}$ detected in $\mathrm{Cu}-\mathrm{Al}-\mathrm{MCM} 41(10)$ and $1.3 \mathrm{wt} \% \mathrm{Cu}$ in Cu-Al-MCM41(15)). Both Cu-Al-MCM41 samples showed significant amounts of fluorine and sulfur, and the extent of disparity between the expected and the experimental values shows that they can only be used, at best for qualitative analysis. The $\mathrm{S} / \mathrm{Cu}$ ratio was $0.44 \mathrm{in} \mathrm{Cu}-\mathrm{Al}-\mathrm{MCM} 41(10)$ and $0.59 \mathrm{in}$ $\mathrm{Cu}-\mathrm{Al}-\mathrm{MCM} 41(15)$, which suggests that part of the sulfur is removed in the thermal treatment of the catalyst (with a starting $\mathrm{S} / \mathrm{Cu}$ ratio of 2). The $\mathrm{F} / \mathrm{Cu}$ ratios were much higher than the theoretical initial value of 6 , which must come from an overstimation of 
fluorine in the analysis. It can be especulated that the fluorine from the triflate remains in the solid by reaction during the thermal treatment.

Using TGA and SEM-EDX data, a hypothesis can be proposed to explain the transformation that $\mathrm{Cu}(\mathrm{OTf})_{2}$ undergoes during the catalyst preparation (Figure 2). Once introduced onto the support, copper(II) triflate interacts with the sodium-counterion and the aluminium site to form an ion-pair. In the course of thermal treatment the fluorine of the triflate reacts with the surface silanol groups, to produce a partially fluorinated surface, and the carbon atom is released in the form of $\mathrm{CO}_{2}$. Some sulfur could be eliminated as either $\mathrm{SO}_{2}$ or $\mathrm{SO}_{3}$, but part of it could also remain on the solid as sulfate anions, which are highly stable (decomposition at $850^{\circ} \mathrm{C}$ on silica [42]).

\section{Figure 2 near here.}

The stability of the MCM41 structure following the deposition of copper and thermal treatment was studied by nitrogen BET isotherms (Figure 3), and the textural properties are summarized in Table 2. The hysteresis, as well as the surface area, pore volume and pore size appear to be not significantly affected by the catalyst preparation.

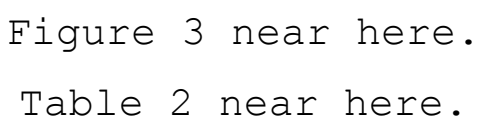

\subsection{Complexation of Cu-Al-MCM41(Ar)}

Having chosen $450^{\circ} \mathrm{C}$ as the suitable temperature for the thermal treatment, the time duration and the atmosphere needed to be decided on. Preparations were conducted using either 4 or $8 \mathrm{~h}$, and the same catalytic results were obtained in both cases, and so 4 $\mathrm{h}$ was deemed to be the optimum condition. The options considered for the atmosphere were either a stream of air or argon.

$\mathrm{Cu}-\mathrm{Al}-\mathrm{MCM} 41(10)$ and $\mathrm{Cu}-\mathrm{Al}-\mathrm{MCM} 41(15)(1.5 \mathrm{wt} \% \mathrm{Cu})$ were heated at $450^{\circ} \mathrm{C}$, for $4 \mathrm{~h}$, in a stream of flowing-argon and the solids obtained from this process will henceforth be referred to as $\mathrm{Cu}-\mathrm{Al}-\mathrm{MCM} 41(\mathrm{X})(A r)$ (with $\mathrm{X}=\mathrm{Si} / \mathrm{Al}$ ratio). $(S)-{ }^{\mathrm{t}} \mathrm{Bu}-\mathrm{azabox}\left(\mathrm{aza}^{\mathrm{t}} \mathrm{Bu}\right.$, Figure 4) was then added by incipient wetness in order to form a chiral immobilized complex, and this solid was used directly as the catalyst in the cyclopropanation of 
styrene with ethyl diazoacetate (Figure 5) in dichloromethane at room temperature, using a stoichiometric quantity of styrene (Table 3).

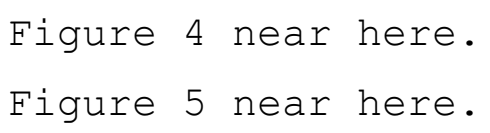

On the basis of the yield and selectivity, the results are very similar to those obtained by the parent homogeneous phase catalyst, and so there is no evidence of a surface or confinement effect. Regarding the performance, when these results are compared to those obtained with the solid prepared by direct incipient wetness impregnation with the $\mathrm{aza}^{\mathrm{t}} \mathrm{Bu}-\mathrm{Cu}(\mathrm{OTf})_{2}$ complex [28], this new method of preparation gives a catalyst much more active, albeit with slightly lower selectivities. Therefore, one can assert that this newer process with thermal treatment provides a more efficient way of binding the complex to the support. Unfortunately, when the catalyst is reused, the yield falls significantly over the course of three cycles, but nonetheless, two interesting facts were observed. Firstly, leaching was not detected and secondly, the enantioselectivities were stable over the course of the recycles. The apparent lack of leaching reinforces the point that the bond between the copper and the support is indeed very strong, and the stable performance in the enantioselectivities, but concurrent loss of yield, shows that the deactivation mechanism does not involve the separation of the ligand from the copper sites.

\section{Table 3 near here.}

In our previous work we described how the supported aza ${ }^{t} \mathrm{Bu}-\mathrm{Cu}$ complex performed better when the reaction was carried out in styrene at $90^{\circ} \mathrm{C}$ [28]. Using just supported copper treated by different methods, without modification by chiral ligand, permits one to see how the support influences the results of reactions, and we studied the effect of the reaction temperature on unmodified $\mathrm{Cu}-\mathrm{Al}-\mathrm{MCM} 41(15)(A r)$. Using a strategy that was originally used to address the problem of improving the reduction of $\mathrm{Cu}$ (II) to $\mathrm{Cu}(\mathrm{I})$, (a pre-requisite of the catalytic cycle) [31], different heating regimes on the cyclopropanation reaction were applied (Table 4): heating at $90^{\circ} \mathrm{C}$ only in the beginning of the reaction (method A), continuos heating at $90^{\circ} \mathrm{C}($ method $\mathrm{B})$ and $100^{\circ} \mathrm{C}(\operatorname{method}$ 
C). The results at 90 and $100^{\circ} \mathrm{C}$ are very similar. A remarkable trend is that trans selectivity smoothly reverses in the course of the cycles, probably due to a change in the nature of the catalytic site. At the beginning when the catalyst is unused, the copper may be at its most tightly bound state to the surface, and this imparts the most significant effect on diastereoselectivity [43]. Gradually, as the catalyst is re-used, the copper can complex with by-products of the cyclopropanation reaction (mainly diethyl maleate or analogous oligomers) and this might move the copper further from the surface. For the homogenous phase reaction, EDA is generally added in $2 \mathrm{~h}$ in order to keep the level of side products formed at the minimum. An important consequence of using excess styrene, at an elevated temperature, is that EDA can be added at a much faster rate (15 min), without observing a loss of yield due to side products being formed.

\section{Table 4 near here.}

Chiral catalysts were prepared using both $\mathrm{Cu}-\mathrm{Al}-\mathrm{MCM} 41(10)(\mathrm{Ar})$ and $\mathrm{Cu}-\mathrm{Al}-$ MCM41(15)(Ar) and tested in cyclopropanation using the newly optimized reaction conditions (Table 5). When compared with Table 3, yields are higher, the enantioselectivities are lower (10-13\% ee lower than at room temperature), and almost 50:50 cis/trans ratio is obtained. There is a remarkable difference in the yields obtained on the different supports, but the selectivities are nearly the same in both cases. The yields with Al-MCM41(10) are significantly higher than with Al-MCM41(15), and this may be related to its larger pore size ( 92 vs $36 \AA$ of pore diameter). The larger pore could mean that there is a more free flow of reagents to and products around the catalytic sites. Regarding recovery, the yield drops from the $4^{\text {th }}$ cycle and by the $6^{\text {th }}$ cycle modified $\mathrm{Cu}-\mathrm{Al}-\mathrm{MCM} 41(10)(A r)$ is almost inactive. Nevertheless, a certain number of re-uses are possible when using the supported complex whereas, at elevated temperature with excess styrene, the reaction is impractical in homogenous phase. Thus, it is not possible to compare the homogeneous and the heterogeneous catalysts under identical conditions, because when copper(II) triflate is heated in styrene it initiates a polymerisation reaction. A certain portion of the inactivation will inevitably arise from pore blocking by the by-products of side reactions, such as oligomerization of styrene. It is remarkable that, taking into account the recycling, these catalysts are very productive with stable selectivities. The modified Cu-Al-MCM41(15) produces a TON 
of 152 (6 runs), with total cis/trans selectivity 48/52, 70\% ee trans and 65\% ee cis. Also in 6 runs, Cu-Al-MCM41(10) leads to a TON of 284, with cis/trans $=49 / 51,74 \%$ ee trans and $69 \%$ ee cis.

Table 5 near here.

\subsection{Complexation of Cu-Al-MCM41(air)}

In the literature, it is described how the thermal treatment of supported copper in a flow of inert gas can produce reductions of $\mathrm{Cu}(\mathrm{II})$ to $\mathrm{Cu}(\mathrm{I})$ and $\mathrm{Cu}(0)[44,45]$. In case this could be detrimental for the activity of the catalyst, the use of a stream of air instead of argon was also tested. This catalyst will be referred as Cu-Al-MCM41(10)(air). This material was then treated in the same way as before by incipient wetness with a solution of aza ${ }^{\mathrm{t}} \mathrm{Bu}$ and tested in the same benchmark cyclopropanation reaction. The most relevant results after treatment in air are compared with those obtained after treatment in Ar in Figure 6.

Depending on the stream used during the catalyst preparation, there is a difference in the enantioselectivities and a different pattern of behaviour in the yields. After thermal treatment in air and modification with aza ${ }^{t} \mathrm{Bu}$ ligand, the yield in the first run is lower than what was obtained in further cycles and also lower than what was obtained in further cycles and also lower than that obtained with the solid treated in argon. From these results it can be inferred that at least a proportion of the copper sites in $\mathrm{Cu}-\mathrm{Al}$ MCM41(Ar) are in the form of $\mathrm{Cu}(\mathrm{I})$, which would be expected to react immediately with diazoacetate in the cyclopropanation. For Cu-Al-MCM41(air) one would expect to find $\mathrm{Cu}(\mathrm{II})$, which needs to be reduced to $\mathrm{Cu}(\mathrm{I})$ in order to react, and this could explain why the first use of the catalyst does not give the highest yield. Notably, upon recycling $\mathrm{Cu}-\mathrm{Al}-\mathrm{MCM} 41$ (air) gives consistent yields of more than $60 \%$ in runs $2-5$. There is a similar consistency in the diastereoselectivity, whose absolute value is a little bit lower than seen in the homogeneous phase, however, it is not clear whether this could be related to either the effect of mesopores or the reaction temperature. At the same time the enantioselectivity remains stable along the five cycles in values of $60 \%$ ee for the trans and $50-56 \%$ ee for the cis isomers, values consistently $12-15 \%$ ee lower than those 
obtained with $\mathrm{Cu}-\mathrm{Al}-\mathrm{MCM} 41(\mathrm{Ar})$. Thus thermal treatment in air gives better stability than the argon-treatment, but leads to a slightly lower enantioselectivity.

$$
\text { Figure } 6 \text { near here. }
$$

\subsection{Continuous flow reactions}

Given the advantages of the continuous flow systems over batch reactions, these solids were tested in a simple continuous reaction setup to see how they would perform. At room temperature, the reagents were fed into a HPLC column packed with the $\mathrm{Cu}-\mathrm{Al}-$ MCM41(air) $(1.5 \mathrm{wt} \% \mathrm{Cu})$ catalyst. Although the flow rates of solvent through the column can be as high as $40 \mathrm{~mL} / \mathrm{h}$, the application of a feed containing the reagents produced a significant resistance and flow rate had to be reduced significantly, down to $1 \mathrm{~mL} / \mathrm{h}$. In the course of one experiment, fractions were collected every $5 \mathrm{~min}$ and analysed by GC. Diastereoselectivity was found to be constant, at around 50:50 cis/trans ratio. Regarding yield (Figure 7), it remains quite stable for $30 \mathrm{~min}$ at values of $40-45 \%$ and then it drops, with an increase in the content of dimerization products (diethyl fumarate and maleate).

$$
\text { Figure } 7 \text { near here. }
$$

Next, the modification of the copper sites with the chiral ligand in a fresh column was attempted by feeding through a dichloromethane solution of $\mathrm{aza}^{\mathrm{t}} \mathrm{Bu}$ into the column through the same syringe feed-system. Upon doing so, the column became completely blocked almost instantly, in spite of using the support with the largest pore size (92 $\AA$ pore diameter). The blocking of the column seems to suggest that dichloromethane is not capable of distributing ligand to all the copper sites. A different solvent might affect the distribution of the ligand throughout the column, and less a tendency to blocking. The requirements of the solvent are to dissolve the ligand, carry it down the pores to the copper sites, and not compete with the ligand at the copper sites. In batch systems dichloromethane has been used as typical solvent for impregnation of meso- [46] and 
microporous materials [47]. On the contrary, Hutchings et al modified CuHY zeolite with bis(oxazoline) ligands in acetonitrile [48], a considerably more polar solvent. In view that the retention factor $\left(R_{f}\right)$ of aza ${ }^{t} \mathrm{Bu}$ on thin layer chromatography plates is zero when dichloromethane is used as an eluent, pore blocking could have been expected. As ethyl acetate is used in the column-chromatography purification of aza ${ }^{\mathrm{t}} \mathrm{Bu}$, this solvent and others with eluotropic strength [49] higher than dichloromethane $\left(\varepsilon^{0}=\right.$ 0.32 ), were considered as alternatives. $20 \mathrm{~mL}$ of $0.01 \mathrm{M}$ solutions of aza ${ }^{\mathrm{t}} \mathrm{Bu}$ in ethyl acetate, acetone, acetonitrile, and methanol ( $\varepsilon^{0}$ values in the range of $\left.0.38-0.73\right)$, were fed into the column and then washed with the same volume of solvent. At the end of the column all the ligand was collected after just one passing. However, all the solvents with higher eluotropic strength than dichloromethane also show a higher coordinating ability index [50], and they can compete more favourably with aza ${ }^{\mathrm{B}} \mathrm{Bu}$ in the coordination to the copper sites. On the other hand, chloroform is a solvent with a slightly lower coordinating ability and eluotropic strength than dichloromethane. In the same test described before $90 \%$ of the ligand was retained on the column, which could be slowly eluted by passing larger amounts of solvent. In spite of this, in principle, better distribution of the ligand inside the pores, the resistance to flow did not completely disappear, but it allowed the test of the column in an enantioselective cyclopropanation.

Once the reactants were fed, the column did become blocked very quickly, but it was possible to obtain a small amount of product. Although the yield was very low (11\%) and the cis/trans ratio was $45 / 55$, the enantiomeric excess were $66 \%$ and $77 \%$ ee for cis and trans cyclopropanes, very similar to the results in batch reactions at $90^{\circ} \mathrm{C}$ with the solid calcined in Ar (Table 5) and significant better than those obtained with the solid calcined in air (Figure 6). Probably in this case the chiral ligand is better distributed inside the pores, leading to a more efficient enantioselective reaction but with a pore blocking that hampers the long-term use of the column.

\section{Conclusions}

In this work, copper was supported on Al-MCM41 using the incipient wetness of a methanol solution of copper(II) triflate, following by thermal treatment in a flow of either air or argon. Using the available evidence from TGA and SEM-EDX, we are able 
to propose a hypothesis for what the structure of the catalytic site could look like. We found that the catalysts prepared in argon gave higher enantioselectivities when modified by the $(S)$-tBu-azabox ligand, also by incipient wetness impregnation, but the catalysts prepared in air gave higher and more consistent yields. According to data described in the literature, it is probable that when the support was thermally treated in argon, part of the copper is reduced to $\mathrm{Cu}(\mathrm{I})$. Although the energy requirement for the thermal treatment makes this procedure less environmentally benign than the direct incipient wetness impregnation, it is worth taking into account the improvement in performance and stability, as well as the need for a calcination in the preparation of the mesoporous support $[35,36]$. The Al-MCM41 support that had the larger pore-size produced yields that were higher than the smaller pored support, which could be explained by there being better diffusion. Finally, we found that in their present form, due to the tendency of column blocking, these catalysts are not suitable for use in a flow reactor.

\section{Acknowledgement}

This research was made possible by the financial support from the Spanish Ministerio de Economía y Competitividad (Project CTQ2011-28124) and the European Commission (NANO-HOST program no. PITN-GA-2008-215193). Dr. Anne Galarneau (Institute Charles Gerhardt, CNRS Montpellier) is gratefully acknowledged for providing the samples of MCM41.

\section{References}

[1] D. E. De Vos, M. Dams, B. F. Sels, P. A. Jacobs, Chem. Rev. 102 (2002) 36153640 .

[2] C. E. Song, S. Lee, Chem. Rev. 102 (2002) 3495-3524.

[3] C. Li, H. Zhang, D. Jiang, Q. Yang, Chem. Commun. (2007) 547-558.

[4] J. M. Fraile, J. I. García, J. A. Mayoral, Chem. Rev. 109 (2009) 360-417.

[5] J. M. Thomas, R. Raja, Acc. Chem. Res. 41 (2008) 708-720.

[6] J. M. Fraile, J. I. García, C. I. Herrerías, J. A. Mayoral, E. Pires, Chem. Soc. Rev. 38 (2009) 695-706. 
[7] G. Desimoni, G. Faita, K. A. Jorgensen, Chem. Rev. 111 (2011) PR284-PR437.

[8] D. Rechavi, M. Lemaire, Chem. Rev. 102 (2002) 3467-3494.

[9] J. M. Fraile, J. I. García, J. A. Mayoral, Coord. Chem. Rev. 252 (2008) 624-646.

[10] J. M. Fraile, J. I. García, C. I. Herrerías, J. A. Mayoral, E. Pires, L. Salvatella, Catal. Today 140 (2009) 44-50.

[11] J. K. Park, S.-W. Kim, T. Hyeon, B. M. Kim, Tetrahedron: Asymmetry 12 (2001) 2931-2935.

[12] T. M. Lancaster, S. S. Lee, J. Y. Ying, Chem. Commun. (2005) 3577-3579.

[13] S. S. Lee, S. Hadinoto, J. Y. Ying, Adv. Synth. Catal. 348 (2006) 1248-1254.

[14] S. S. Lee, J. Y. Ying, J. Mol. Catal. A 256 (2006) 219-224.

[15] J. Lim, S. N. Riduan, S. S. Lee, J. Y. Ying, Adv. Synth. Catal. 350 (2008) 12951308 .

[16] R. J. Clarke, I. J. Shannon, Chem. Commun. (2001) 1936-1937.

[17] J.-M. Lee, J. Kim, Y. Shin, C.-E. Yeom, J. E. Lee, T. Hyeon, B. M. Kim, Tetrahedron: Asymmetry 21 (2010) 285-291.

[18] A. R. Silva, H, Albuquerque, S. Borges, R. Siegel, L. Mafra, A. P. Carvalho, J. Pires, Microporous Mesoporous Mater. 158 (2012) 26-38.

[19] A. R. Silva, L. Carneiro, A. P. Carvalho, J. Pires, Catal. Sci. Technol. 3 (2013) $2415-2424$.

[20] M. A. O. Lourenço, L. Carneiro, A. Mayoral, I. Díaz, A. R. Silva, P. Ferrerira, J. Catal. 320 (2014) 63-69.

[21] Z.-H. Li, Z.-M. Zhou, X.-Y. Hao, J. Zhang, X. Dong, Y.-Q. Liu, Chirality 24 (2012) 1092-1095.

[22] Y. Wan, P. McMorn, F. E. Hancock, G. J. Hutchings, Catal. Lett. 91 (2003) 145148.

[23] S. Telalović, U. Hanefeld, Appl. Catal. A 372 (2010) 217-223.

[24] As an example of immobilization on inorganic mesoporous ordered materials: P. Piaggio, P. McMorn, C. Langham, D. Bethell, P. C. Bulman-Page, F. E. Hancock, G. J. Hutchings, New J. Chem. 22 (1998) 1167-1169.

[25] As an example of immobilization on organically modified mesoporous ordered materials: S. Xiang, Y. Zhang, Q. Xin, C. Li, Chem. Commun. (2002) 2696-2697. [26] As an example of electrostatic immobilization on mesoporous ordered materials: $\mathrm{H}$. H. Wagner, H. Hausmann, W. F. Hölderich, J. Catal. 203 (2001) 150-156. 
[27] As an example of immobilization through hydrogen bonding on mesoporous ordered materials: F. M. de Rege, D. K. Morita, K. C. Ott, W. Tumas, R. D.Broene, Chem. Commun. (2000) 1797-1798.

[28] R. A. Feldman, J. M. Fraile, Appl. Catal. A 485 (2014) 67-73.

[29] J. M. Fraile, J. I. García, J. A. Mayoral, T. Tarnai, M. A. Harmer, J. Catal. 186 (1999) 214-221.

[30] J. M. Fraile, J. I. García, C. I. Herrerías, J. A. Mayoral, M. A. Harmer, J. Catal. 221 (2004) 532-540.

[31] J. M. Fraile, J. I. García, C. I. Herrerías, J. A. Mayoral, O. Reiser, A. Socuéllamos, H. Werner, Chem. Eur. J. 10 (2004) 2997-3005.

[32] P. Piaggio, P. McMorn, D. Murphy, D. Bethell, P. C. Bulman Page, F. E. Hancock, C. Sly, O. J. Kerton, G. J. Hutchings, J. Chem. Soc., Perkin Trans. 2 (2000) 2008-2015. [33] S. Taylor, J. Gullick, P. McMorn, D. Bethell, P. C. Bulman Page, F. E. Hancock, F. King, G. J. Hutchings, J. Chem. Soc., Perkin Trans. 2 (2001) 1724-1728.

[34] N. A. Caplan, F. E. Hancock, P. C. Bulman Page, G. J. Hutchings, Angew. Chem., Int. Ed. Engl. 43 (2004) 1685-1688.

[35] J. M. Kim, J. H. Kwak, S. Jun, R. Ryoo, J. Phys. Chem. 99 (1995) 16742-16747.

[36] A. Galarneau, M. Cangiotti, F. di Renzo, F. Sartori, M. F. Ottaviani, J. Phys. Chem. B 110 (2006) 20202-20210.

[37] M. Wang, H. Jiang, Z. C. Wang, J. Therm. Anal. Calorim. 85 (2006) 751-754.

[38] J. Tian, H. Jiang, H. Gong, Z. Sun, J. Therm. Anal. Calorim. 77 (2004) 825-831.

[39] V. Sage, J. H. Clark, D. J. Macquarrie, J. Catal. 227 (2004) 502-511.

[40] K. Wilson, A. Rénson, J. H. Clark, Catal. Lett. 61 (1999) 51-55.

[41] E. Loeser, S. Babiak, M. DelaCruz, P. Karpinski, J. Chromatogr. Sci. 49 (2011) $57-62$.

[42] J. C. Halle, K. H. Stern, Corros. Sci. 20 (1980) 1139-1142.

[43] J. I. García, B. López-Sánchez, J. A. Mayoral, E. Pires, I. Villalba, J. Catal. 258 (2008) 378-385.

[44] G. Zhang, J. Long, X. Wang, W. Dai, Z. Li, L. Wu, X. Fu, New J. Chem. 33 (2009) 2044-2050.

[45] A. Tschöpe, M. L. Trudeau, J. Y. Ying, J. Phys. Chem. B 103 (1999) 8858-8863.

[46] H. H. Wagner, H. Hausmann, W. F. Hölderich, J. Catal. 203 (2001) 150-156. 
[47] A. R. Silva, H. Albuquerque, A. Fontes, S. Borges, Â. Martins, A. P. Carvalho, J. Pires, Ind. Eng. Chem. Res. 50 (2011) 11495-11501.

[48] S. Taylor, J. Gullick, P. McMorn, D. Bethell, P. C. Bulman-Page, F. E. Hancock, F. King, G. J. Hutchings, J. Chem. Soc., Perkin Trans. 2 (2001) 1714-1723.

[49] L. R. Snyder, Principles of Adsorption Chromatography, Marcel Dekker, New York, 1968.

[50] R. Díaz-Torres, S. Álvarez, Dalton Trans. 40 (2011) 10742-10750. 
Table 1. Transition points from TGA of $\mathrm{Cu}(\mathrm{OTf})_{2}$ and $\mathrm{Zn}(\mathrm{OTf})_{2}$ deposited on different materials by incipient wetness. ${ }^{\mathrm{a}}$

\begin{tabular}{lllll}
\hline Triflate & Support & $\mathrm{T}_{1}\left({ }^{\circ} \mathrm{C}\right)$ & $\mathrm{T}_{\mathrm{m}}\left({ }^{\circ} \mathrm{C}\right)$ & $\mathrm{T}_{2}\left({ }^{\circ} \mathrm{C}\right)$ \\
\hline $\mathrm{Cu}$ & none & 400 & 460 & 475 \\
& Silica $(70-200 \mu \mathrm{m})$ & 323 & 356 & 367 \\
& Silica $(35-70 \mu \mathrm{m})$ & 326 & 363 & 373 \\
& MCM41 & 341 & 400 & 441 \\
& Al-MCM41(15) & 280 & 306 & 329 \\
& Al-MCM41(10) & 276 & 306 & 327 \\
& none & 488 & 527 & 533 \\
& Al-MCM41(15) & 284 & 310 & 340
\end{tabular}

a $1.5 \mathrm{wt} \% \mathrm{Cu}($ or $\mathrm{Zn}$ ). The solids were dried under vacuum for $12 \mathrm{~h}$ prior TGA (from r.t. to $500^{\circ} \mathrm{C}$ at $10^{\circ} \mathrm{C} / \mathrm{min}$ ). 
Table 2. Composition and textural properties of the mesoporous supports and the $\mathrm{Cu}-\mathrm{Al}-$ MCM41 (1.5 wt $\% \mathrm{Cu})$ catalysts.

\begin{tabular}{lllll}
\hline Support & $\begin{array}{l}\% \mathrm{Cu} \\
\text { loading }\end{array}$ & $\begin{array}{l}\text { Surface } \\
\text { area }\left(\mathrm{m}^{2} / \mathrm{g}\right)\end{array}$ & $\begin{array}{l}\text { Pore volume } \\
(\mathrm{ml} / \mathrm{g})\end{array}$ & $\begin{array}{l}\text { Pore diameter } \\
(\AA)\end{array}$ \\
\hline Al-MCM41(10) & - & 628 & 1.2 & 92 \\
& 1.5 & 532 & 1.4 & 99 \\
Al-MCM41(15) & - & 860 & 0.6 & 36 \\
& 1.5 & 930 & 0.7 & 36 \\
MCM41 & - & 967 & 0.7 & 36 \\
\hline
\end{tabular}


Table 3. Results of the cyclopropanation of styrene with EDA catalyzed by $\mathrm{Cu}-\mathrm{Al}$ MCM41(10)(Ar) modified with aza ${ }^{\mathrm{t}} \mathrm{Bu}$.

\begin{tabular}{lllllll}
\hline Conditions $^{\mathrm{a}}$ & Run & Yield & $\mathrm{TON}^{\mathrm{b}}$ & cis/ & \multicolumn{2}{l}{$\%$ ee } \\
\cline { 6 - 8 } & & $(\%)$ & & trans & cis & trans \\
\hline Homogeneous & - & 44 & 55 & $24: 76$ & 87 & 93 \\
Incipient wetness $^{\mathrm{c}}$ & 1 & 3 & 4 & $24: 76$ & 82 & 91 \\
Heterogeneous & 1 & 46 & 58 & $36: 64$ & 79 & 87 \\
& 2 & 17 & 21 & $38: 62$ & 81 & 87 \\
& 3 & 8 & 10 & $36: 64$ & 68 & 70
\end{tabular}

a At room temperature, EDA $(2.5 \mathrm{mmol})$ in $\mathrm{CH}_{2} \mathrm{Cl}_{2}(0.5 \mathrm{~mL})$ slowly added $(2 \mathrm{~h})$ to a solution of styrene $(2.5 \mathrm{mmol})$ in $\mathrm{CH}_{2} \mathrm{Cl}_{2}(2 \mathrm{~mL})$ containing the catalyst $(0.025 \mathrm{mmol}$ $\mathrm{Cu}) .{ }^{\mathrm{b}} \mathrm{Mol}$ of cyclopropanes produced per mol of copper. ${ }^{\mathrm{c}}$ Catalyst prepared by incipient wetness of the preformed aza ${ }^{\mathrm{t}} \mathrm{Bu}-\mathrm{Cu}(\mathrm{OTf})_{2}$ complex (ref. [28]). 
Table 4. Results of the cyclopropanation of an excess of styrene with EDA catalyzed by $\mathrm{Cu}-\mathrm{Al}-\mathrm{MCM} 41(15)(\mathrm{Ar})$.

\begin{tabular}{lllll}
\hline Conditions $^{\mathrm{a}}$ & Run & Yield (\%) & TON $^{\mathrm{b}}$ & cis/trans \\
\hline A (initial heating at & 1 & 17 & 21 & $55: 45$ \\
$\left.90^{\circ} \mathrm{C}\right)$ & 2 & 40 & 50 & $52: 48$ \\
& 3 & 43 & 54 & $50: 50$ \\
& 4 & 43 & 54 & $47: 53$ \\
& 5 & 38 & 48 & $45: 55$ \\
B (continuous & 1 & 34 & 43 & $56: 44$ \\
heating at $\left.90^{\circ} \mathrm{C}\right)$ & 2 & 60 & 75 & $54: 46$ \\
& 3 & 59 & 74 & $51: 49$ \\
& 4 & 56 & 70 & $48: 52$ \\
C (continuous & 5 & 61 & 76 & $43: 57$ \\
heating at $\left.100^{\circ} \mathrm{C}\right)$ & 2 & 61 & 76 & $53: 47$ \\
& 3 & 59 & 74 & $49: 51$ \\
& 4 & 65 & 81 & $43: 57$ \\
& 5 & 59 & 74 & $38: 62$
\end{tabular}

${ }^{a}$ EDA $(2.5 \mathrm{mmol})$ in $\mathrm{CH}_{2} \mathrm{Cl}_{2}(0.5 \mathrm{~mL})$ slowly added $(15 \mathrm{~min})$ to a suspension of catalyst $(0.025 \mathrm{mmol} \mathrm{Cu})$ in styrene $(2 \mathrm{~mL})$ heated at the required temperature. ${ }^{\mathrm{b}}$ Mol of cyclopropanes produced per mol of copper. 
Table 5. Results of the cyclopropanation of an excess styrene with EDA at $90^{\circ} \mathrm{C}$ catalyzed by $\mathrm{Cu}-\mathrm{Al}-\mathrm{MCM} 41(\mathrm{Ar})$ modified with aza ${ }^{\mathrm{t}} \mathrm{Bu}{ }^{\mathrm{a}}$

\begin{tabular}{lllllll}
\hline Support & Run & $\begin{array}{l}\text { Yield } \\
\text { (\%) }\end{array}$ & TON $^{\mathrm{b}}$ & cis/ & \multicolumn{2}{l}{$\%$ ee } \\
\cline { 5 - 7 } & & & & trans & cis & trans \\
\hline Al-MCM41(10) & 1 & 69 & 86 & $49: 51$ & 68 & 74 \\
& 2 & 53 & 66 & $50: 50$ & 70 & 76 \\
& 3 & 54 & 68 & $50: 50$ & 71 & 74 \\
& 4 & 38 & 48 & $47: 53$ & 68 & 74 \\
& 5 & 33 & 41 & $47: 53$ & 69 & 72 \\
& 6 & 37 & 46 & $48: 52$ & 69 & 73 \\
& 7 & 8 & 10 & $50: 50$ & 66 & 62 \\
& 1 & 29 & 36 & $44: 56$ & 62 & 68 \\
& 2 & 31 & 39 & $46: 54$ & 65 & 68 \\
& 3 & 34 & 43 & $48: 52$ & 66 & 70 \\
& 4 & 21 & 26 & $51: 49$ & 66 & 72 \\
& 5 & 20 & 25 & $49: 51$ & 65 & 70 \\
& 6 & 17 & 21 & $51: 49$ & 65 & 72
\end{tabular}

${ }^{\mathrm{a}}$ Reaction conditions as in Table $4 .{ }^{\mathrm{b}}$ Mol of cyclopropanes produced per mol of copper. 


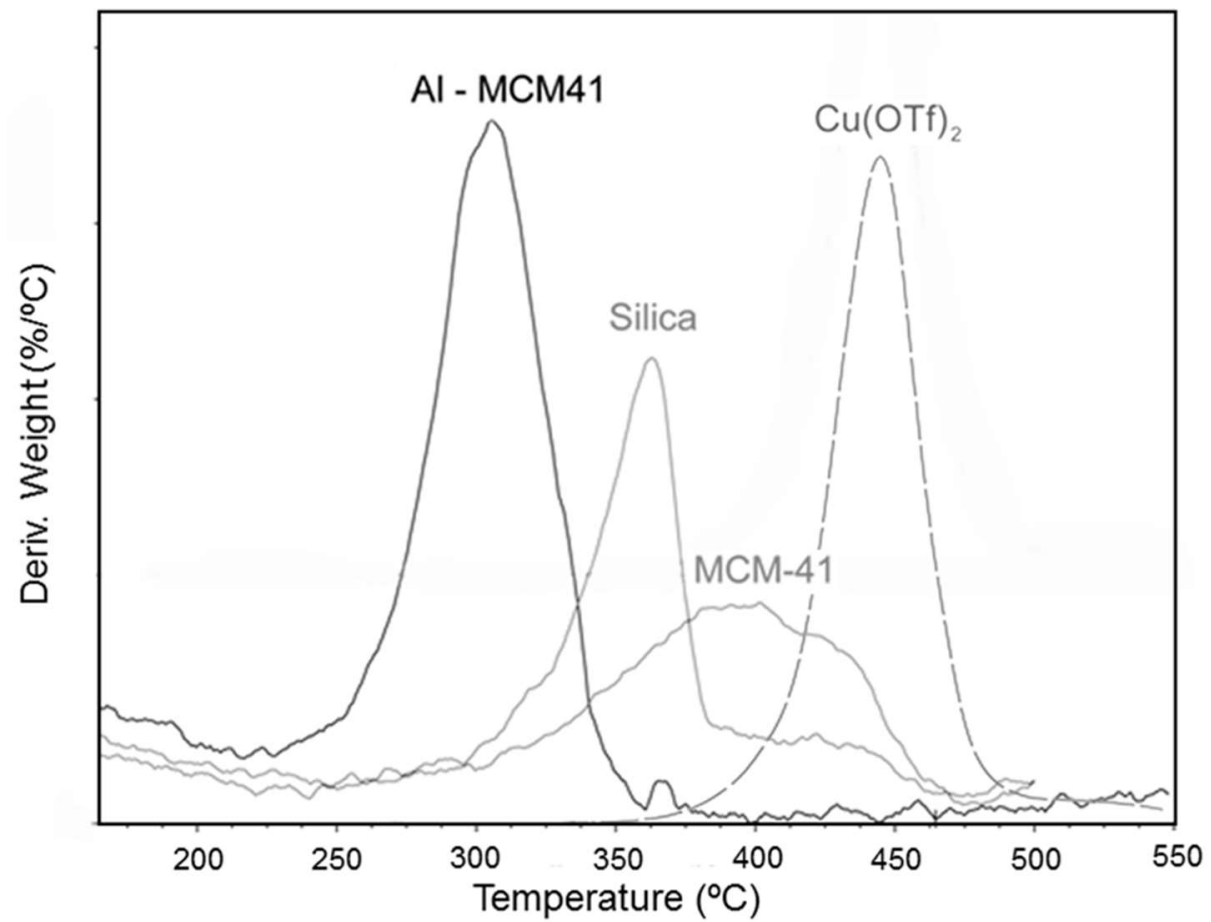

Figure 1. TGA curves of $\mathrm{Cu}(\mathrm{OTf})_{2}$ in pure form and deposited on different solids by incipient wetness. 


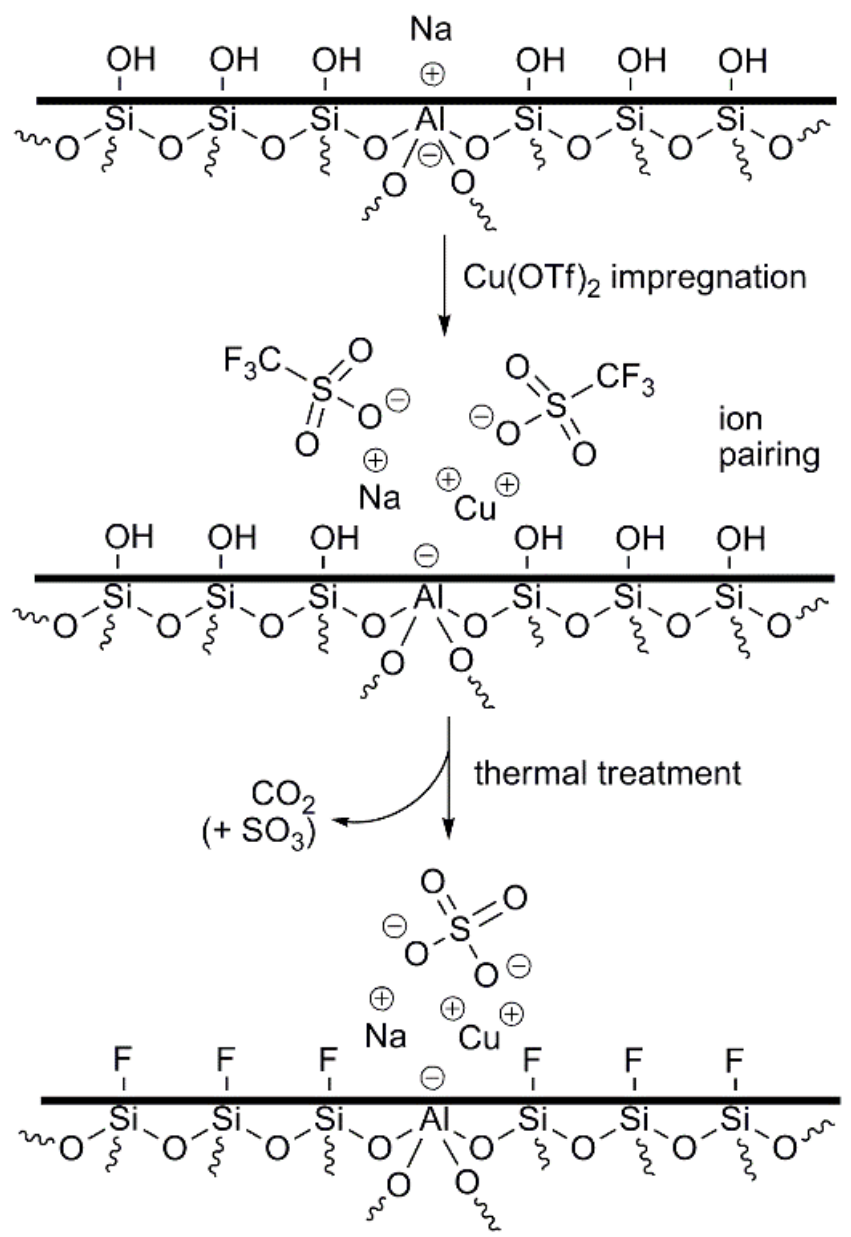

Figure 2. Hypothesis for copper(II) triflate transformation after impregnation on AlMCM41 and thermal treatment. 


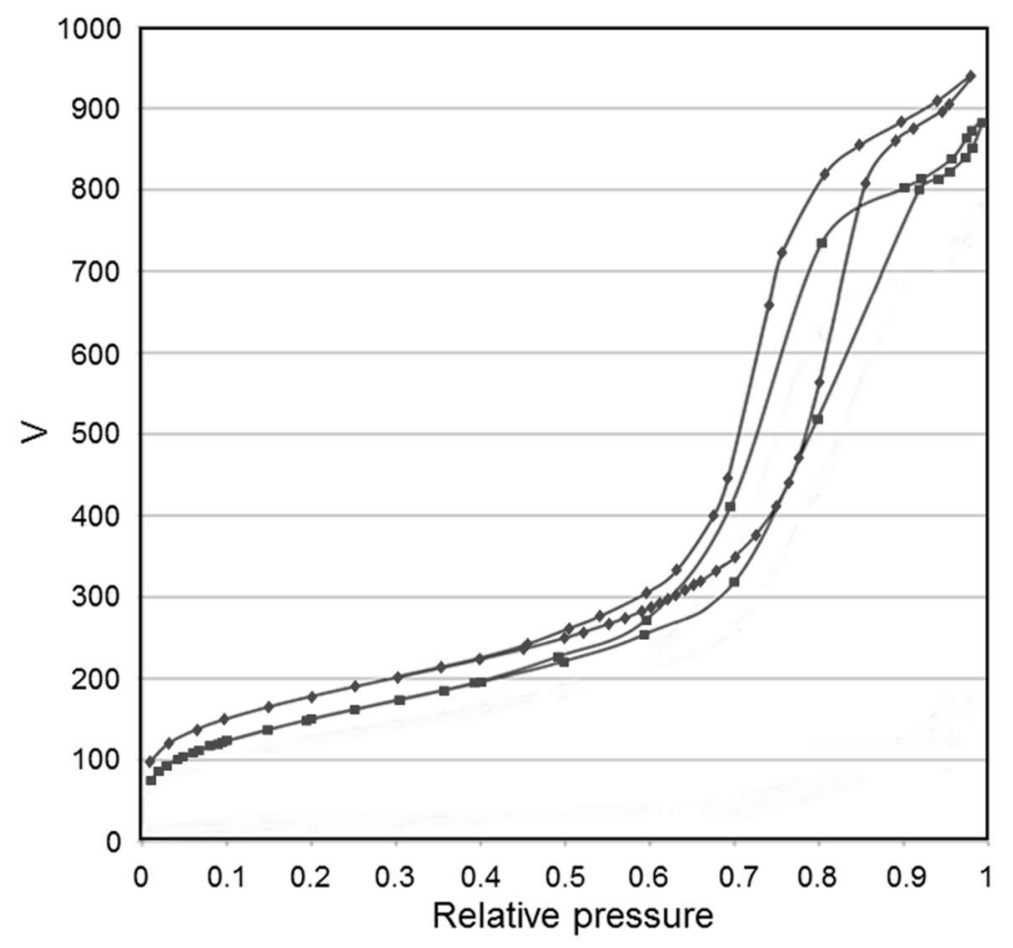

Figure 3. Nitrogen BET isotherms of Al-MCM41(10) (blue) and Cu-Al-MCM41(10) with $1.5 \mathrm{wt} \% \mathrm{Cu}$ (red).

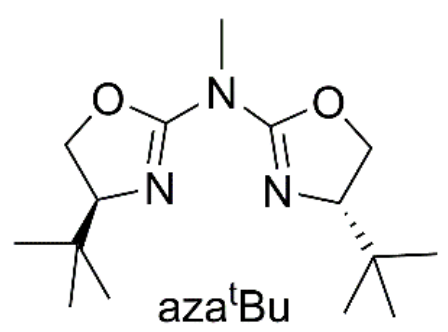

Figure 4. $(S)-{ }^{\mathrm{t}} \mathrm{Bu}$-azabox ligand $\left(\mathrm{aza}^{\mathrm{t}} \mathrm{Bu}\right)$.
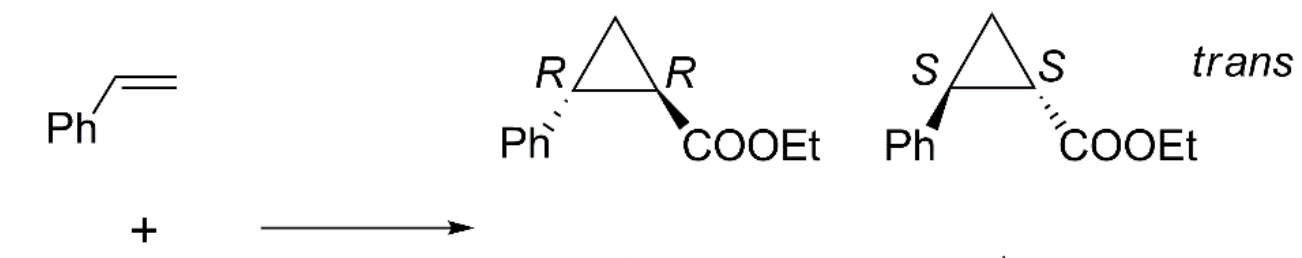

\section{$\mathrm{N}_{2} \mathrm{CHCOOEt}$}

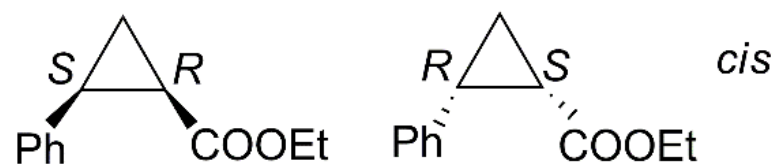

Figure 5. Cyclopropanation of styrene with ethyl diazoacetate (EDA). 


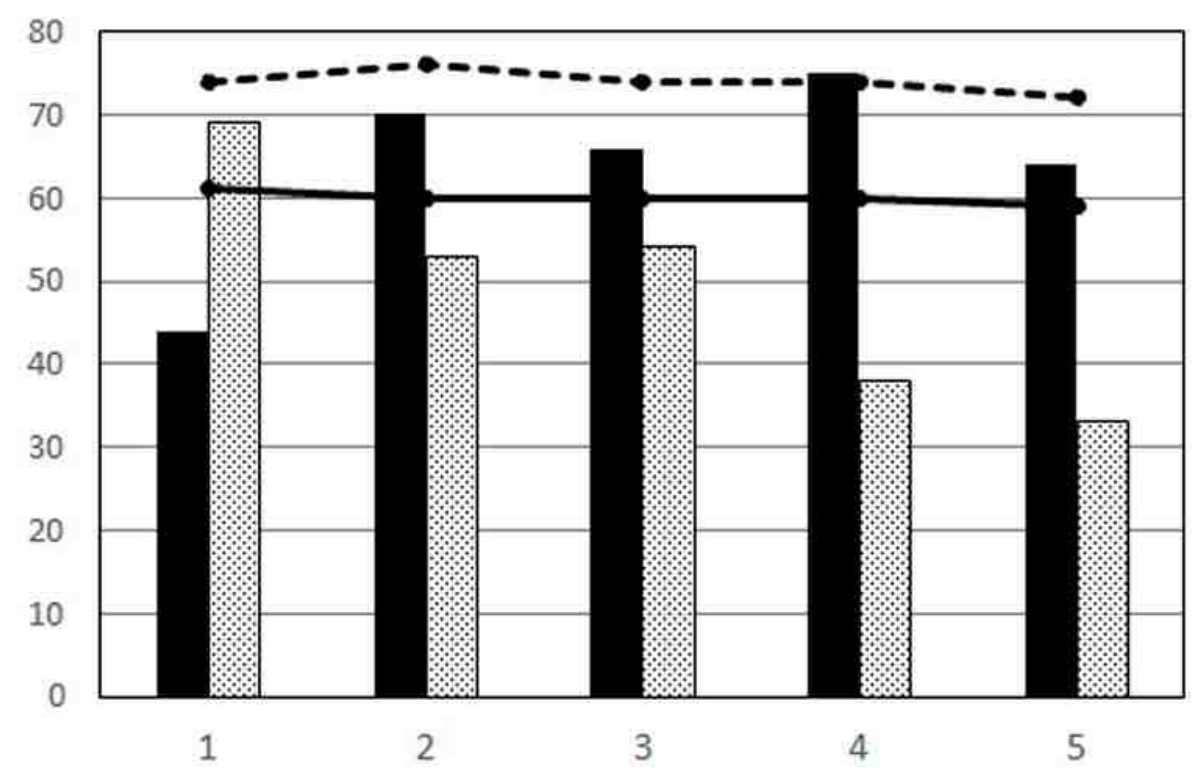

Figure 6. Results (yields in bars, \%ee trans in lines) obtained in the cyclopropanation of styrene with ethyl diazoacetate catalyzed by $\mathrm{Cu}-\mathrm{Al}-\mathrm{MCM} 41(10)$ modified with aza ${ }^{\mathrm{t}} \mathrm{Bu}$ : treated in air (black) and $\operatorname{Ar}$ (dotted).

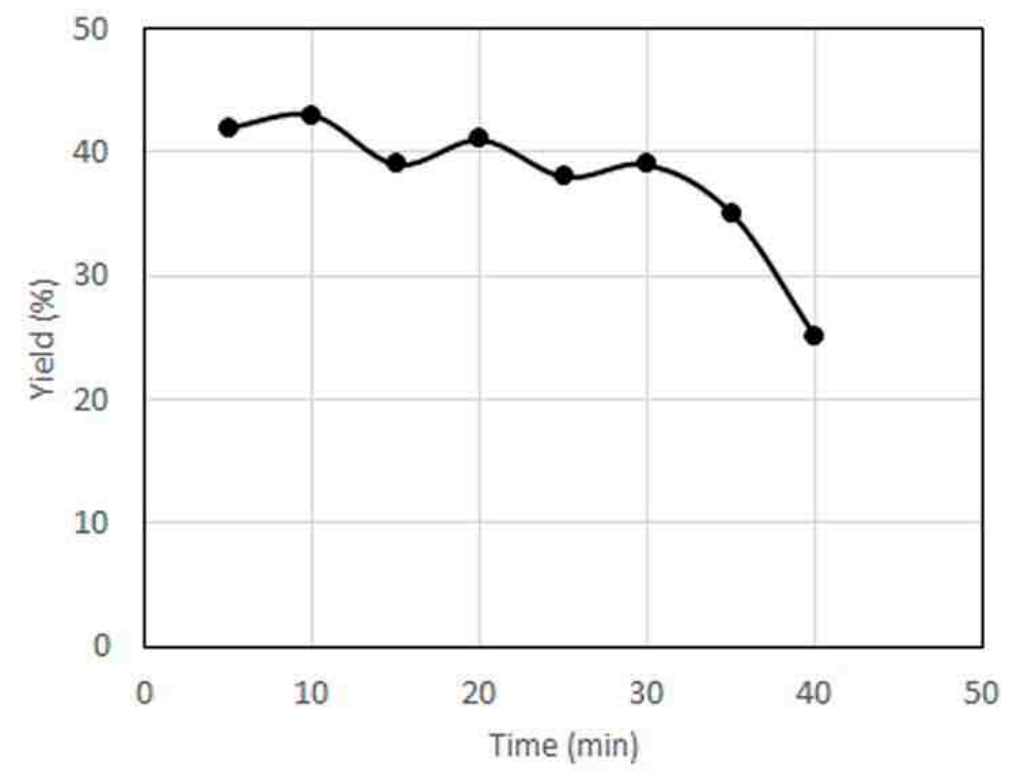

Figure 7. Yields obtained in the cyclopropanation of styrene with ethyl diazoacetate catalyzed by $\mathrm{Cu}-\mathrm{Al}-\mathrm{MCM} 41(10)($ air $)(1.5 \mathrm{wt} \% \mathrm{Cu})$ in the continuous flow setup. 